\title{
Early Intervention Provider Use of Child Caregiver-Teaching Strategies
}

Philippa Campbell, PhD

Thomas Jefferson University

Catherine Ehret-Coletti, MS

Thomas Jefferson University

Follow this and additional works at: https://jdc.jefferson.edu/otfp

Part of the Occupational Therapy Commons

Let us know how access to this document benefits you

\section{Recommended Citation}

Campbell, PhD, Philippa and Ehret-Coletti, MS, Catherine, "Early Intervention Provider Use of Child Caregiver-Teaching Strategies" (2013). Department of Occupational Therapy Faculty

Papers. Paper 28.

https://jdc.jefferson.edu/otfp/28

This Article is brought to you for free and open access by the Jefferson Digital Commons. The Jefferson Digital Commons is a service of Thomas Jefferson University's Center for Teaching and Learning (CTL). The Commons is a showcase for Jefferson books and journals, peer-reviewed scholarly publications, unique historical collections from the University archives, and teaching tools. The Jefferson Digital Commons allows researchers and interested readers anywhere in the world to learn about and keep up to date with Jefferson scholarship. This article has been accepted for inclusion in Department of Occupational Therapy Faculty Papers by an authorized administrator of the Jefferson Digital Commons. For more information, please contact: JeffersonDigitalCommons@jefferson.edu. 
As submitted to:

Infants and Young Children

And later published as:

Early Intervention Provider Use of Child Caregiver-Teaching Strategies

Philippa H. Campbell, PhD

Catherine Ehret-Coletti, MS

Volume 26, Number 3, September 2013, pages: 235-248

DOI:10.1097/IYC.0b013e318299918f

Keywords: Early intervention; caregiver-teaching strategies; 


\section{Early Intervention Provider Use of Caregiver-Teaching Strategies}

Most current early intervention approaches emphasize the importance of a provider role as teacher or coach, a role in which providers give parents or other caregivers information about how to optimize children's growth and development (Stremel \& Campbell, 2007). However, few studies have examined the information that should be provided for caregivers or how this information is best delivered to caregivers although a number of rating scales are able to distinguish between roles of direct service provider for the child (e.g., traditional) and triadic interaction among provider, caregiver, and child (Campbell \& Sawyer, 2007; Salisbury \& Cushing, 2013). Related factors such as how to train professionals to implement a broader role than direct provider to the child, provider or caregiver expectations about the provider role, or caregiver or child outcomes when providers play a teaching or coaching role, also, have received little investigation.

A number of factors compound our understanding of this broader provider role. One primary factor is the inconsistency within the literature and among researchers about what behavior or actions occur when providers are helping families learn what to do with their children. Frequently used terms are collaborative consultation (Basu, Salisbury, \& Thorkildsen, 2010; Cambray-Engstrom \& Salisbury, 2010; Klein \& Chen, 2008; Woods, Wilcox, Friedman, \& Murch, 2011), coaching (Dunn, Cox, Foster, Mische-Lawson, \& Tanquary, 2012; Friedman, Woods, \& Salisbury, 2012; Keilty, 2010; Rush \& Shelden, 2011), or caregiver teaching (Campbell \& Sawyer, 2009; Colyvas, Sawyer, \& Campbell, 2010). A set of definitions, proposed by Friedman and colleagues (2012), are the basis of a measure of coaching. Eight practices define a construct called coaching. Two additional practices are included but are part of a non-coaching category. The eight coaching strategies include: (a) conversation and 
information sharing (CIS); (b) observation (OB); (c) direct teaching (DT); (d) demonstration with narration (DEM/DN); (e) guided practice with feedback (GPF); (e) caregiver practice with feedback (CPF); (f) joint interaction (JI); (g) problem-oriented reflection (PS/R); and two noncoaching strategies: (a) provider works directly with the child (CF) and (b) other. Several different studies have used these definitions to quantify providers' actions during home visits (Friedman et al., 2012; Salisbury \& Cushing, 2013; Marturana \& Woods, 2012).

A narrower definition of the provider teaching role has been used to measure caregiver teaching in other studies (Campbell \& Sawyer, 2007; 2009; Colyvas, Sawyer, \& Campbell, 2010; Fleming, Sawyer, \& Campbell, 2011; Wilcox, Campbell, \& Lamorey, 2008; Wilcox, 2012). These researchers define five explicit caregiver-teaching strategies that generally comprise a subset of the broader set of coaching practices defined by Friedman et al (2012). Caregiver-teaching strategies include demonstration with narrative (DN), caregiver practice with feedback (CPF), guided practice (GP), conversation (CIS), and problem oriented reflection (POR). Other practices, some of which are defined by Friedman et al. (2012) as coaching, are considered as non-caregiver-teaching strategies including joint interaction with the child (JIC), working with child without explanation (i.e., direct hands on intervention; direct teaching; WCE), observation (OB), and other $(\mathrm{O})$ (e.g., caregiver not in room; provider on cell phone) (Campbell \& Sawyer, 2008). Both groups of researchers have measured provider-caregiver interactions by rating videotaped samples of home visits and recording the occurrence of coaching practices or caregiver-teaching strategies at 30 -second intervals.

When comparing outcomes across studies using these similar rating codes and procedures, there is little difference in provider use of practices but distinct differences in how those practices are viewed. Because practices such as joint interaction with the child are viewed 
as an acceptable coaching practice (e.g. Friedman et al, 2012; Salisbury \& Cushing, 2013) but not as a caregiver-teaching practice (Campbell \& Sawyer, 2008), providers appear to be making positive changes in use of coaching practices because an increase across time is noted in occurrence of joint interaction with the child. Both systems separately code caregiver-teaching practices (demonstration with narrative; caregiver practice with feedback; problem-oriented reflection), but because of the low frequency of occurrence, in the Friedman et. al (2012) approach, these practices are scored separately but combined into a broader category labeled "specific coaching strategies." The Campbell and Sawyer (2008) rating system reports these practices separately despite equally low-frequency occurrence. Combining these practices into one category allows statistical significance and effect sizes to be reported for basically insignificant changes. For example, Marturana and Woods (2012) reported both statistically significant changes and large effect size in provider use of specific coaching strategies when the use of these practices increased from less than $5 \%$ to approximately $5 \%$ of rated intervals. The specific number of coded intervals were not reported, but if 30 minutes (60 30-s intervals) of tape were rated, use of these combined (i.e., specific coaching) practices increased from less than 1.5 to 1.5 minutes across a 30 minute sample.

Several authors have acknowledged providers' lack of adoption of coaching or caregiverteaching practices (e.g., Campbell \& Sawyer, 2007; 2009; Friedman et. al, 2012; Salisbury \& Cushing, 2013; McWilliam, 2012). Researchers have attempted to understand why providers may not change practices by assessing perspectives via surveys and interviews (e.g., Fleming et al., 2011; Salisbury, Cambray-Engstrom, \& Woods, 2012; Salisbury, Woods, \& Copeland, 2010; Sawyer \& Campbell, 2009; 2012). Various approaches designed to change provider practice have been studied by numerous researchers (e.g. Campbell \& Sawyer, 2009; Marturana \& 
Woods, 2012; Wilcox, 2012), but the patterns of provider change seem to be consistent across studies; the percent of intervals where providers use direct hands-on intervention with the child decrease across time points and the percent of intervals where the caregiver-provider-child are together (i.e., joint interaction with the child; triadic interaction) increase. Conversation generally occurs in the greatest number of intervals and often scores higher than any other coaching or teaching practice both at baseline (i.e., pretest) and in any other subsequent time points. The specific practices of demonstration with narrative, caregiver practice with feedback, or problem-oriented reflection occur in very few intervals and, as a whole, show little change in any study from baseline through any subsequent post-test measures. Problem-oriented reflection is generally the strategy with the lowest occurrence across all studies.

A myriad of reasons are suggested to explain providers' low use of coaching or caregiver teaching in early intervention and their limited adoption of these practices even when training has been provided (e.g., Campbell \& Sawyer, 2009; Marturana \& Woods, 2012). One suggested reason relates to a preservice education emphasis, particularly for those trained in the therapies, on a direct and hands-on model that may bias providers away from use of coaching or caregiver teaching (Bruder \& Dunst, 2005; Campbell, Chiarello, Milbourne, \& Wilcox, 2009) or interfere with their ability to practice in more family-centered ways (Campbell, 2013; McWilliam, 2010; Wilcox \& Woods, 2011). Others characterize preservice education as well as many professional development opportunities as teaching providers to use intervention techniques in isolation rather than by embedding techniques into a functional, activity, or routine context (Campbell \& Sawyer, 2009; McWilliam, 2012). Other reasons for limited use of coaching or caregiver teaching are attributed to family preference. For example, providers are more likely to teach families when the family specifically asks to be taught than when families 
expect providers to work directly with the child for the duration of the home visit (e.g., Fleming, Sawyer, \& Campbell, 2011.) Similarly, providers are more likely to provide information and advice or engage in problem-solving when the concern is initiated by the caregiver and the information is within the providers' discipline preparation (e.g., Salisbury, Woods, \& Copeland, 2010; Sawyer \& Campbell, 2009; 2012).

Professional development opportunities are often targeted to increasing providers' competence in use of intervention techniques for the child without an emphasis on competence for working with, coaching, or teaching caregivers to implement intervention strategies with their children (Colyvas, Sawyer, \& Campbell, 2010; McWilliam, 2010; Rush \& Shelden, 2012; Sawyer \& Campbell, 2009). Therefore, providers may not know how to collaborate with, coach, or teach adults (Fowler, Yates, \& Ostrosky, 2011.) An implementation perspective provides a lens through which practice adoption may be viewed regardless of the reasons for lack of adoption. Conceptually, users of any new skill must have knowledge of the skill and the ability to demonstrate it under some set of conditions. From this perspective, early intervention providers need to both know about caregiver-teaching strategies and be able to demonstrate them under at least one set of conditions before they are likely to be able to use them within most every-day practice situations. Other strategies such as engaging a caregiver in joint interaction or providing advice, resources, or other verbal information via conversation are possibly more familiar and comfortable ways of interacting with caregivers than through more direct teaching strategies (Sawyer \& Campbell, 2012).

In this study, we were interested in learning more about provider knowledge and understanding of caregiver-teaching strategies because providers across studies and situations consistently have shown extremely low use of these strategies. Recommended practices and 
studies about practice implementation (Fixen, Naoom, Blasé, Friedman, \& Wallace, 2005; Stremel \& Campbell, 2007) as well as professional development (e.g., Snyder, Hemmeter, Meeker, Kinder, Pasia, \& McLaughlin, 2012) suggest that professionals need opportunities to understand and demonstrate practices before being able to apply the practice successfully within all of the varied real-life situations encountered with children and families in early intervention. We focused on looking at provider competence by examining accuracy in illustrating and correctly labeling various caregiver-teaching strategies when providers used them with provideridentified caregivers and children. We hypothesized that some caregiver-teaching strategies would be illustrated more frequently than others and that play activities would be a more frequent intervention context than other types of activities or routines.

\section{Method}

\section{Participants}

Participants included 78 early intervention service providers who completed an activity where they submitted up to three videotaped segments illustrating their use of teaching strategies with provider-selected caregivers. Three providers were eliminated from the sample because none of the their segments reflected caregiver-teaching strategies. Table 1 lists demographic characteristics of 75 providers who submitted at least one taped segment illustrating caregiver teaching. A majority (98.7\%) were female and Caucasian (72.9\%). Special instructors (i.e., education; 41.3\%) were the largest discipline group although occupational and physical therapy and speech and language pathology were also represented. More than half $(54.8 \%)$ of the providers were employed as independent contractors and a quarter (26.0\%) of the group had 10 or fewer children on their caseloads. The mean years of experience in early intervention was 8.66 years. 
A total of 99 children/families participated in caregiver-teaching videotape segments. Providers obtained demographic information from $94(95 \%)$ of the families although all participating families did not provide answers to all demographic questions. A majority (95.7\%) of the respondents were female with $77.4 \%$ of the families described as two-parent homes. A third of the sample were Caucasian (37.2\%) or African-American (35.1\%); the remainder were Latino/Hispanic (21.3\%), multiracial $(4.3 \%)$ or Asian $(2.1 \%)$. Of those families providing information about annual income, more than half (57.5\%) reported incomes of less than $\$ 31,000$ per year. Respondents reported their children's delays or disabilities as mild (49.4\%), moderate (37.1\%), or severe $(13.5 \%)$. Only $44.1 \%$ of the children had received formal diagnoses; these included cerebral palsy, vision or hearing impairment, autism, or Down syndrome.

\section{Procedure}

Participants attended a 3-hour training session about a 4-component approach to early intervention services and then completed a 2-hour, one-time session for each of the four components (i.e., establishing outcomes, child intervention, caregiver teaching, progress monitoring). During the 2-hour session about caregiver teaching, providers watched a presentation with short video-clips illustrating various caregiver-teaching strategies used during early intervention home visits and participated in two case study role plays of caregivers being taught by providers. The five teaching strategies are described on Table 2 and included: (a) demonstration with narrative; (b) caregiver practice with feedback; (c) guided practice; (d) conversation and information sharing; and (e) problem-oriented reflection. Following the session, participants decided which three teaching strategies they wished to illustrate and made videotapes of themselves using each of these strategies. Each videotape was submitted with written information about four areas: (a) what the provider was trying to teach the caregiver; (b) 
why the illustrated activity/routine was selected; (c) what strategies were used to teach the caregiver (e.g., demonstration with narrative); and (d) any challenges faced in implementing the caregiver teaching. Participants provided their own consent and completed a demographic questionnaire and also obtained caregiver videotape consent and demographic information.

\section{Videotape Segments}

A total of 205 viewable videotape segments were submitted. A segment was defined as: (a) service provider verbally introduced the segment(s) on a videotape; (b) camera shut off and turned back on (different day, different child, and/or different activity) when segments were recorded on the same tape; or (c) segments were submitted on separate tapes/DVDs. Three teaching segments were available from 60 of the 78 (77\%) providers, two segments from 7 (9\%) providers, and one segment from 11 (14\%) providers. However, all of these submitted videotapes did not include examples of caregiver-teaching strategies.

Each segment was viewed by an independent rater who judged whether or not a teaching strategy was used and recorded information for each segment about: (a) length; (b) primary functional skill being addressed for the child; (c) teaching strategy used by the provider; and (d) a narrative description of the segment contents. No teaching was observed in 37 of the $205(18 \%)$ segments. No teaching included situations such as providers and caregivers interacting jointly with children without any teaching occurring, providers working directly with the child, or caregivers not being present. The 37 non-teaching segments were submitted by 24 $(31 \%)$ participants. Providers $(n=3)$ and families $(n=4)$ were eliminated from the sample when none of their submitted videotapes illustrated caregiver teaching. The 168 teaching segments illustrating caregiver teaching were retained. Each segment ranged in length from 1 to 40 minutes $(M=10.28, S D=6.46)$. 


\section{Analysis}

The narrative description was used to classify each of the 168 segments as either activitybased or discussion-based teaching. A total of $135(80 \%)$ of the teaching segments were classified as activity-based because an activity that included the child was the basis for the caregiver teaching (e.g., how to teach a child to stand up or use a spoon); 33 (20\%) segments were classified as discussion-based because teaching the child a specific skill, even if the child were present, was not the central focus of the discussion (e.g, how to obtain assistance with heating bills; types of foods to try with the child). The activity-based segments were further coded into one of 11 activities and routines in which young children commonly participate (i.e. mealtime, bath time, playing with family members, participating in family errands). Teaching strategies for both the activity-based and discussion-based segments were then coded using the five caregiver-teaching strategy categories: (a) demonstration with narrative; (b) caregiver practice with feedback, (c) guided practice; (d) conversation and information sharing; and (e) problem-oriented reflection. Narrative descriptions of the 33 discussion-based segments were further analyzed qualitatively to describe the contents of provider-caregiver discussions. The primary functional skill being taught to the child was coded by the independent rater while watching each of the activity-based teaching segments. Information submitted by the provider as well as the rater's narrative descriptions was consulted when clarification was needed or when the rater could not clearly identify the functional skill emphasis.

Information was entered into the data base from the provider-completed forms for each video segment. This included the provider label for the illustrated tape segment (i.e., strategies used to teach the caregiver), what the provider was trying to teach the caregiver, and the activity or routine being used. Not all providers submitted information about all areas for each segment 
or provided sufficiently clear information (e.g., provider trying to teach caregiver to help child.) The independent rater's teaching segment codes were compared with the providers' written descriptions and percent agreement was calculated by dividing the agreements by the sum of the agreements plus disagreements and multiplying by 100 .

Inter-rater reliability was established by having a second rater code $27(20 \%)$ of the 135 activity-based segments and 7 (20\%) of the 33 discussion segments resulting in an total interrater sample of 34 segments, or $20 \%$ of the 168 caregiver-teaching segments. The second rater was given a sheet of terms the original coder used to describe functional skill, teaching strategy, and observed activity. These terms were used by the second coder to record information from the segments including (a) the context of the teaching (activity or discussion), (b) the activity in which teaching was embedded, if applicable, (c) the functional skill being addressed for the child, and (d) the teaching strategy being implemented. Percent agreement was calculated for each of the four categories and then averaged to obtain an inter-rater reliability score. The raters attained $94 \%$ agreement in how they identified the context of teaching, $94 \%$ for functional skill identification, $97 \%$ for identification of teaching strategy, and $88 \%$ agreement in naming the activity in the segment. The average percent agreement across all categories was $93 \%$.

\section{Results}

Our goal was to determine the extent to which early intervention providers were able to label and demonstrate a set of five caregiver-teaching strategies and to examine possible associations between caregiver-teaching strategy, intervention context (i.e., activity; skill), or child's degree of disability. 


\section{Use and Labeling of Caregiver-Teaching Strategies}

To examine the extent to which providers were able to demonstrate and correctly label caregiver-teaching strategies, percent of agreement was calculated between the labels given to each segment by the provider and an independent rater. The rater identified 37 of the 205 provider-submitted segments as not including observable caregiver-teaching strategies.

Providers did not identify the caregiver-teaching strategy for $13(35 \%)$ of the segments; another $11(30 \%)$ were labeled as modeling, a term describing a no- teaching situation where caregivers presumably watched while providers worked directly with the child without discussing or explaining what they were doing. Only $13(35 \%)$ of the rater-identified non-teaching segments were identified by the provider as teaching. These were labeled as demonstration with narrative $(n=4)$, caregiver practice with feedback $(n=7)$, or conversation $(n=2)$. The percent of agreement for this subsample was $66 \%$.

The remaining 168 segments were classified by the independent rater into two types of teaching: activity-based or discussion-based. Segments were viewed and labeled by the independent rater and matched to labels submitted by the provider with each taped segment. Providers did not include sufficient descriptions of the teaching strategy for 24 of the 168 teaching tapes. The percent of agreement for caregiver-teaching strategy was $83 \%$ for the activity-based and $89 \%$ for the discussion-based teaching segments with an overall percent of agreement of $86 \%$ for all tapes.

\section{Caregiver-Teaching Strategies}

Providers were asked to submit three videotape examples of different caregiver-teaching strategies but could choose whichever three strategies they wished to illustrate. Conversation or problem-oriented reflection was used exclusively in the 33 (20\%) discussion-based segments. 
Activity-based segments included: caregiver practice with feedback (59:35\%); demonstration with narrative $(33 ; 21 \%)$; guided practice $(31 ; 18 \%)$; and problem-oriented reflection $(\mathrm{n}=12$; 7\%). Overall, the most frequently illustrated caregiver-teaching strategy was caregiver practice with feedback.

Caregiver teaching was provided within the context of a child-based activity in 135 of the segments. The most frequently illustrated activity was play $(95 ; 70 \%)$. The remaining 40 segments were classified as non-play and included mealtimes (14\%), physical activities (7\%) or routines such as bathtime, morning or evening routines, errands, or leaving the house which were represented in the remaining $9 \%$ of the segments. Play activities were further coded into more descriptive categories. Playing with toys in an isolated activity was the most frequently selected play activity (50\%), followed by pre-academic activities (e.g. books, songs/rhymes; 23\%), and combined play where play with toys was combined with other types of play (27\%).

Table 3 provides the number and percent of times that caregiver-teaching strategies were used in activity-based (i.e., play, non-play) and discussion teaching situations. As can be seen, demonstration with narrative, caregiver practice with feedback, and guided practice were more likely to occur in activities that were play-based than in non-play-based activities. To determine any significance in association of caregiver-teaching strategies with play or non-play activity situations, caregiver-teaching strategies were combined into three categories: (a) demonstration (e.g., situations where the provider demonstrates with the child and provides explanation of what is being done while the caregiver observes); (b) practice (e.g., a combination of caregiver practice with feedback and guided practice where a caregiver has the opportunity to actually practice directly with the child while the provider gives feedback and guidance); and (c) discussion (e.g., conversation, information sharing, and problem-oriented reflection (e.g., 
providers and caregivers interact and discuss verbally including jointly addressing particular issues.) A chi-square analysis was conducted to determine associations between the three caregiver-teaching categories and play/non-play activities and yielded $X^{2}(2, \mathrm{~N}=168)=$ 45.094, $\mathrm{p}=<.001$. Practice was associated with play activities significantly more frequently than with non-play activities.

Conversation and information sharing and problem-oriented reflection were more likely to occur during discussion-based than activity-based teaching segments and generally occurred equally in play/non-play situations. The independent rater's narrative description of the 33 discussion segments were further analyzed by coding descriptions into qualitative themes to characterize discussion content. Almost half $(\mathrm{n}=16 ; 48 \%)$ of the segments included general discussions of the child's current status or developmental progress including discussions about a specific area of development (e.g., mobility; language; behavior). Another $36 \%(\mathrm{n}=12)$ were discussions of specific techniques (e.g., infant massage; sign language) or recommendations (e.g., audiology examination; visit to feeding clinic). Only two segments included discussions of an activity or routine that was problematic for the family; one was a discussion of strategies to try so that the child's hair could be cut and another was ideas for getting the child to sleep.

\section{Functional Skills}

The 135 activity-based segments were coded to describe the primary functional skill being emphasized. Only one skill was identified for each segment but a number of different skills were observed across the segments. These were classified into the following functional skill categories: (a) communication $(n=61 ; 45 \%)$; (b) getting around $(n=27 ; 20 \%)$; (c) functional use of arms and hands $(\mathrm{n}=21 ; 16 \%)$; $(\mathrm{d})$ personal care routines including eating (12; $9 \%)$; (e) socialization and behavior regulation (4;3\%); and (f) other (10; 7\%). Table 4 shows the 
type, frequency, and percent of caregiver-teaching strategies used when the functional skill was communication or something other than communication. As can be seen, similar frequency and percent of caregiver-teaching strategies were used to teach all functional skills with the exception of conversation and problem-oriented reflection which occurred more frequently when the functional skill was not communication. The five caregiver-teaching strategies were recoded into the three categories described earlier (i.e., demonstration; practice; conversation and reflection) and Chi-square analyses were conducted with the 135 activity-based teaching segments to examine association functional skill (i.e., communication or not communication) category. There were no significant differences $\left[X^{2}(2, \mathrm{~N}=135)=.3210, \mathrm{p}=.321\right]$.

Play activities appeared to be a frequent context for teaching communication skills. Chisquare analyses were conducted between functional skill (i.e., communication or not communication) and play (i.e., play or not play) categories and yielded a $X^{2}(1, \mathrm{~N}=135)=$ 9.351, $\mathrm{p}<.002$ indicating that play activities were used significantly more than non-play activities when communication was the targeted functional skill.

\section{Degree of Disability}

The degree of the child's disability, as identified by the caregiver, was available for 119 of the 135 teaching segments. A majority of the segments included children whose degree of disability was characterized as mild $(n=54 ; 46 \%)$. Almost a third included children classified as moderate $(\mathrm{n}=45 ; 38 \%)$, and in only $17 \%(\mathrm{n}=20)$ of the segments were children classified as severe. Chi-square analyses between degree of disability and the three categories of caregiver teaching showed no significant association $\left[X^{2}(2, \mathrm{~N}=130)=1.628, \mathrm{p}=.443\right]$. 


\section{Discussion}

A number of studies conducted by varied researchers document the limited amounts of time that providers spend explicitly teaching caregivers during home visits. Attempts have been made to increase the amount of coaching or caregiver teaching that providers use through various types of professional development but these activities have shown limited success in substantially increasing provider use of caregiver-teaching strategies. Explanations for why providers do not use coaching or explicit caregiver teaching have been numerous with one of the predominant explanations being that providers do not know how to teach because they are not only not taught this skill during professional preparation but are taught a competing approach of direct hands-on intervention.

The most important finding in this present study is that early intervention providers are able to accurately illustrate individual caregiver-teaching strategies when specifically asked to do so. Furthermore, they are able to accurately label or describe the demonstrated strategy, thereby suggesting that lack of provider knowledge or ability to use these strategies may not be a primary reason for why caregiver teaching does not occur during home visits. Caregiver teaching with practice was the most frequently demonstrated strategy and may be a provider-preferred strategy as this strategy is frequently used by early intervention providers in studies of coaching or caregiver-teaching practices (e.g., Colyvas, Sawyer, \& Campbell, 2010; Friedman, Woods, \& Salisbury, 2012; Salisbury, Cambray-Engstrom, \& Woods, 2012).

Play, primarily toy play, was the most frequently illustrated activity in the caregiverteaching segments, a finding that is reflected in many other studies of early intervention home visits where playing with toys is what providers seem to do with children in their homes (e.g., Campbell \& Sawyer, 2009; Freidman, Woods, \& Salisbury, 2012; McWilliam, 2012). Teaching 
strategies that allowed caregivers to practice with their children were significantly associated with a play context for intervention and occurred less frequently in non-play activities.

Strategies such as conversation or problem-oriented reflection occurred more frequently when play was not the context of activity-based teaching or when the teaching was totally discussionbased. There was no association of caregiver-teaching strategy use to the degree of the child's disability.

The circumstances under which different caregiver-teaching strategies are used and the reasons for selecting one strategy over another have been considered in only a few studies. When providers responded to a survey that presented various types of situations to which they responded by identifying optimal caregiver-teaching strategies, providers selected conversation for those activities in which the provider was unlikely to physically present (e.g., bedtime; family outings) and practice types of teaching for toy play and other activity contexts that could be designed by the provider (Sawyer \& Campbell, 2012). Other researchers discuss use of teaching strategies within the context of principles of adult learning and suggest that strategies used should match the caregiver's learning style and preference (Marturana \& Woods, 2012; Woods et. al, 2011). The segments submitted by providers in this study are compatible with the findings in the Sawyer and Campbell (2112) survey where strategies such as showing (i.e., demonstration with narrative) or practice (i.e., caregiver practice with feedback; guided practice) are only used when provider-child-caregiver are all part of the same activity context.

\section{Limitations}

Caregivers of children in early intervention are typically a very diverse group in terms of characteristics such as racial/ethnic background, primary language spoken in the home, educational level, or socioeconomic status. Caregivers may also demonstrate diversity in less 
frequently or easily measured characteristics such as self-direction, assertiveness, engagement, self-efficacy, or confidence and may also have expectations for both their role and that of the provider. While the 99 caregivers who were taught by 75 providers in this study were relatively diverse in terms of basic demographic characteristics, each caregiver was selected by the provider and, therefore, may have been caregivers whom the providers identified as being motivated, or willing to be taught, or willing to participate in being videotaped - characteristics that may make these caregivers different for unidentified reasons. An additional limitation is that the 168 taped segments were not all independent from each other since these segments represented 99 children, each of whom were used from one to three times to illustrate a caregiver-teaching strategy. However, the central question in this study was whether or not providers could demonstrate the use of three different caregiver-teaching strategies with caregivers and children of their choice. The extent to which providers can actually use a practice that they demonstrated one time with and across multiple families/children on their caseloads (e.g., generalize) was not examined in this study and is not known. Caregiver, provider, and child characteristics likely influence generalization as do the professional development or other strategies used to help providers implement a particular practice across multiple variances that may be facilitators and make the application process easier or complications and make the process more difficult. Our real challenge in promoting use of these caregiver-teaching strategies is in enabling providers to use these strategies successfully in real-life situations with the real-life children and families who make up their caseloads.

\section{Implications and Future Research}

A variety of professional development approaches have not significantly increased provider use of caregiver-teaching strategies in their day to day practice. However, the reasons 
for the limited success of any number of strategies (e.g., group training; distance learning; personal or video mentoring; adherence to fidelity practices) are not clearly understood. Future research could provide more information about why caregiver-teaching practices are and are not used in practice and these factors could potentially shape future implementation or professional development activities. This present study illustrates one set of conditions under which providers can implement these teaching strategies, albeit with one self-selected child and family.

Results also suggest possible links between the activity used as the context for caregiver (and child) teaching, functional skill, and caregiver-teaching strategy that warrant more investigation. For example, what impact on caregiver-teaching strategies might result if professional development simply targeted reductions in toy play? If providers were able to reduce or eliminate the amount of time where toy play is used as the activity-based teaching context and increase the amount of time where other activity contexts are used, would frequency of caregiver teaching increase? Similarly, a majority of children who are enrolled in early intervention programs are likely to be provided with intervention addressing communication. In this study, communication and play were significantly associated suggesting that play may be the primary activity in which communication intervention is based. If providers were able to teach communication outside of a context of play, to what extent would the use of other activities influence use of caregiver-teaching strategies? The bottom-line is that research efforts need to be directed to finding the point at which providers will accept and aggressively want to use these strategies as part of their practice.

\section{Conclusion}

The amount of research and number of publications about recommended practices during early intervention home visits has increased across the past five years. The field may be 
acquiring a better understanding of the factors supporting and hindering practice implementation and how these play out in adoption across providers, families, and children. In recent years, one emphasis has been on identifying practices that providers should use in work with caregivers and children during home visits. The results of this study document that providers can accurately identify and demonstrate caregiver-teaching strategies under a fixed set of conditions. Perhaps our future efforts need to focus less on teaching providers about these strategies and more on helping them implement strategies across variations in activity contexts and functional skills and with various children and caregivers. 


\section{References}

Basu, S., Salisbury, C. L., \& Thorkildsen, T. A. (2010). Measuring collaborative consultation practices in natural environments. Journal of Early Intervention, 32, 127-150. doi: $10.1177 / 1053815110362991$

Bruder, M.B. \& Dunst, C.J. (2005). Personnel preparation in recommended early intervention practices: Degree of emphasis across disciplines. Topics in Early Childhood Special Education, 25, 25-33.

Cambray-Engstrom, E., \& Salisbury, C. (2010). An exploratory case study of providers' collaborative consultation practices with Latina mothers during home visits. Infants \& Young Children, 23, 262-274.

Campbell, P.H. (2013). Occupational and physical therapy. In Batshaw, L. M., Roizen, J. N., \& Lotrecchiano, R. G. (Eds.), Children with Disabilities: Seventh Edition (pg. 599-612). Baltimore, MD: Paul H. Brookes.

Campbell, P. H., Chiarello, L., Milbourne, S. , \& Wilcox, M. J. (2009). Preparing therapists as effective practitioners in early intervention. Infants \& Young Children, 22(1), 21-31. doi: 10.1097/01.IYC.0000343334.26904.92

Campbell, P. H. \& Sawyer, L. B. (2007). Supporting learning opportunities in natural settings through participation-based services. Journal of Early Intervention, 29, 287-304. doi: $10.1177 / 105381510702900402$

Campbell, P. H. \& Sawyer, L. B. (2008). Natural environments rating scale - revised. Thomas Jefferson University, Child and Family Studies Research Programs. 
Campbell, P. H. \& Sawyer, L. B. (2009). Changing early intervention providers' home visiting skills through participation in professional development. Topics in Early Childhood Special Education, 28, 219-234. doi: 10.1177/0271121408328481

Colyvas, J. L., Sawyer, L. B., \& Campbell, P. H. (2010). Identifying strategies early intervention occupational therapists use to teach caregivers. American Journal of Occupational Therapy, 64, 776-785. doi: 10.5014/ajot.2010.09044

Dunn, W., Cox, J., Foster, L., Mische-Lawson, L., \& Tanquary, J. (2012). Impact of a contextual intervention on child participation and parent competence among children with autism spectrum disorders: A pre-test-post-test repeated-measures design. American Journal of Occupational Therapy, 66, 520-528. doi: 10.5014/ajot.2012.004119.

Fixsen, D. L., Naoom, S.F., Blasé, K. A., Friedman, R. M., \& Wallace, F. (2005). Implementation research: A synthesis of the literature. Tampa: University of South Florida, Louis de la Parte Florida Mental Health Institute, The National Implementation Research Network.

Fleming, J. L., Sawyer, L. B., \& Campbell, P. H. (2011). Early intervention providers' perspectives about implementing participation-based practices. Topics in Early Childhood Special Education, 30, 233-244. doi: 10.1177/0271121410371986

Friedman, M., Woods, J., \& Salisbury, C. (2012). Caregiver coaching strategies for early intervention providers: Moving toward operational definitions. Infants \& Young Children, $25,62-82$.

Fowler, S. A., Yates, T., \& Ostrosky, M. M. (2011). Professional development for early childhood intervention: Current status and future directions. In C. Groark \& S. P. Maude (Eds.), Early childhood intervention: Shaping the future for children with special needs 
and their families, Vol. 2. Proven and promising practices (pp. 95-122). Santa Barbara, CA: ABC-CLIO.

Keilty, B. (2010). Effective practices in early intervention for families and their infants and toddlers. New York City, presentation to New York City Local Early Intervention Coordinating Council. Retrieved 2/23/2013: http://www.nyc.gov/html/doh/downloads/pdf/earlyint/effective-practices.pdfhttp://

Klein, D. M., \& Chen, D. (2008). Home visiting practices in early intervention with infants with disabilities: An exploratory study. Early Childhood Services, 2, 207-224.

Marturana, E. R., \& Woods, J. J. (2012). Technology-supported performance-based feedback for early intervention home visiting. Topics in Early Childhood Special Education, 32, 14-23. doi: $10.1177 / 0271121411434935$

McWilliam, R. A. (2010). Routines-based early intervention: Supporting young children with special needs and their families. Baltimore, MD: Paul H. Brookes

McWilliam, R. A. (2012). Implementing and preparing for home visits. Topics in Early Childhood Special Education, 31, 224-231. doi: 10.1177/0271121411426488

Rush, D. D., \& Shelden, M. L. L. (2011). The Early Childhood Coaching Handbook. Brookes Publishing Company. PO Box 10624, Baltimore, MD 21285.

Salisbury, C., Cambray-Engstrom, E., \& Woods, J. (2012). Providers' reported and actual use of coaching strategies in natural environments. Topics in Early Childhood Special Education, 32, 88-98. doi: 10.1177/0271121410392802

Salisbury, C. L., \& Cushing, L. S. (2013). Comparison of triadic and provider-led intervention practices in early intervention home visits. Infants \& Young Children, 26, 28-41. doi: 10.1097/IYC.0b013e3182736fc0 
Salisbury, C. L., Woods, J., \& Copeland, C. (2010). Provider perspectives on adopting and using collaborative consultation in natural environments. Topics in Early Childhood Special Education, 30, 132-147. doi: 10.1177/1053815112455363

Sawyer, L. B. E., \& Campbell, P. H. (2009). Beliefs about participation-based practices in early intervention. Journal of Early Intervention, 31, 326-343. doi: 10.1177/1053815109351536

Sawyer, B. E., \& Campbell, P. H. (2012). Early interventionists' perspectives on teaching caregivers. Journal of Early Intervention, 34, 104-124.

Snyder, P., Hemmeter, M. L., Meeker, K. A., Kinder, K., Pasia, C., \& McLaughlin, T. (2012). Characterizing key features of the early childhood professional development literature. Infants \& Young Children, 25, 188 -212.

Stremel, K., \& Campbell, P.H. (2007). Implementation of early intervention within natural environments. Early Childhood Services, 1, 83-105.

Unger, D. G., Jones, C. W., Park, E., \& Tressell, P. A. (2001). Promoting involvement between low-income single caregivers and urban early intervention programs. Topics in Early Childhood Special Education, 21, 197-212. doi: 10.1177/027112140102100401

Wilcox, M. J. (2012). A look inside early intervention: What's going on? Presentation at the American Speech Hearing and Language Association annual conference, November 28, 2012.

Wilcox, M. J., Campbell, P.H., Lamorey, S. (2008). Strategies Used by Early Intervention Personnel to Teach Families, CREI Biannual Meeting, San Diego, February 21, 2008. Wilcox, M. J. \& Woods, J. (2011). Participation as a basis for developing early intervention outcomes. Language, Speech, and Hearing Services in Schools, 42, 365-378. doi: $10.1044 / 0161-1461$ 
Woods, J. J., Wilcox, M. J., Friedman, M., \& Murch, T. (2011). Collaborative consultation in natural environments: Strategies to enhance family-centered supports and services.

Language, Speech, and Hearing Services in Schools, 42, 379-392. doi: 10.1044/0161-1461 
Table 1

Early Intervention Service Provider Characteristics $(n=75)$

Percent Frequency

Discipline

$\begin{array}{lcc}\text { Education } & 41.3 & 31 \\ \text { SLP } & 22.7 & 17 \\ \text { OT } & 20.0 & 15 \\ \text { PT } & 13.3 & 10 \\ \text { Other } & 2.7 & 2\end{array}$

Ethnicity

Caucasian

African American

Latino/Hispanic

Asian

Other

Education

Doctoral degree

Master's degree
72.9

17.1

4.3

1.4

1

12

3

3

3.0

4

48.0

36 


$\begin{array}{lcc}\text { Bachelor's degree } & 44.0 & 33 \\ \text { Associate's degree } & 4.0 & 3\end{array}$

Employment status

Independent contractor

Full-time

Part-time

Size of Caseload

Fewer than 5

6-10

$11-15$

$16-20$

$21-30$

More than 30
40

38.7

5.3

4

9

10

13.7

10

8.2

6

22.7

17

28.8

21

Years of experience in discipline
Mean $(S D)$
$15.14(10.14)$

Months of experience in early intervention

$\operatorname{Mean}(S D)$

$8.83(5.61)$ 
Table 2

Teaching behavior classification used for coding videotapes

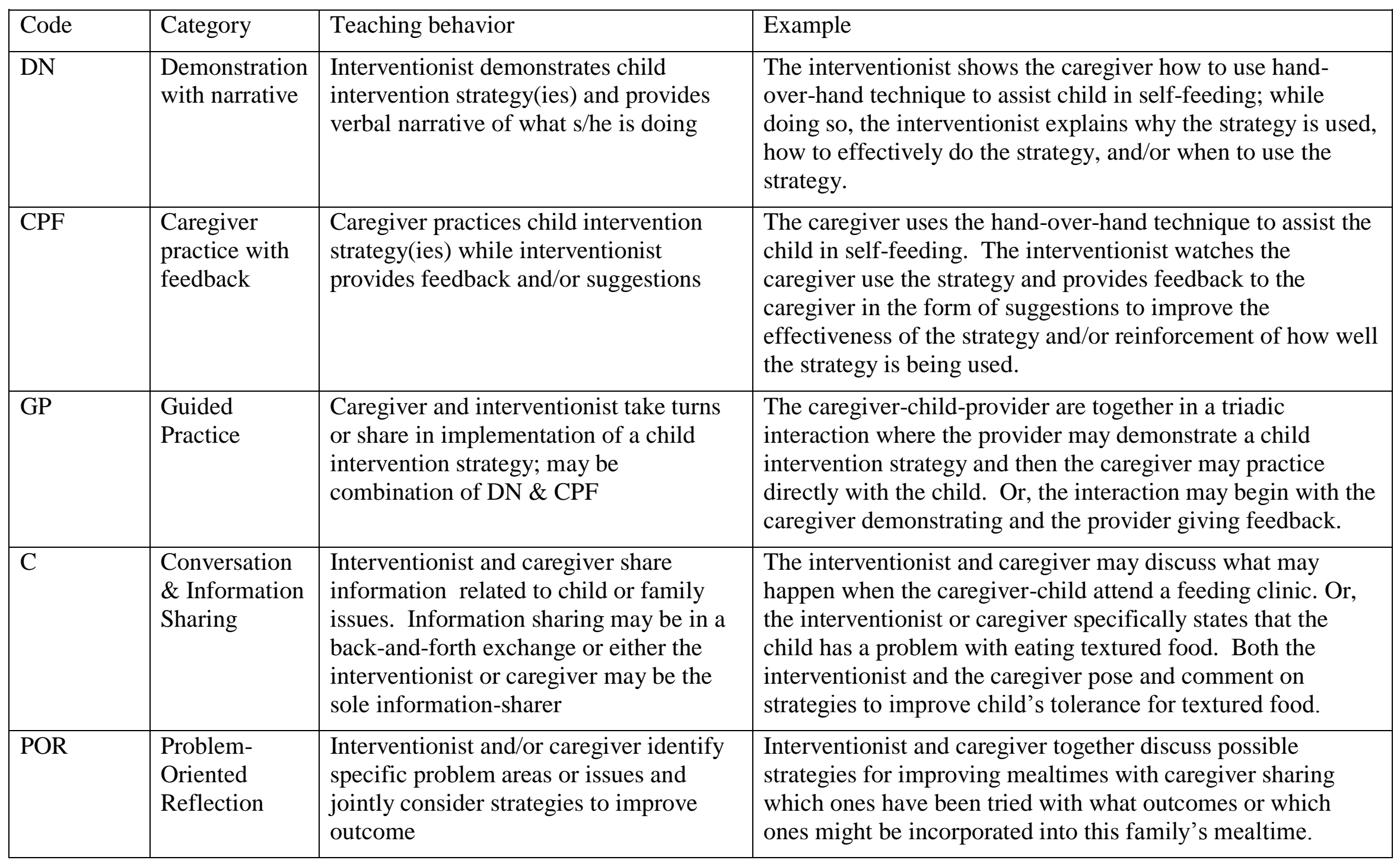


Table 3

Caregiver-Teaching Strategies Used in Activity-Based $(n=135)$ \& Discussion-Based $(n=33)$

Segments

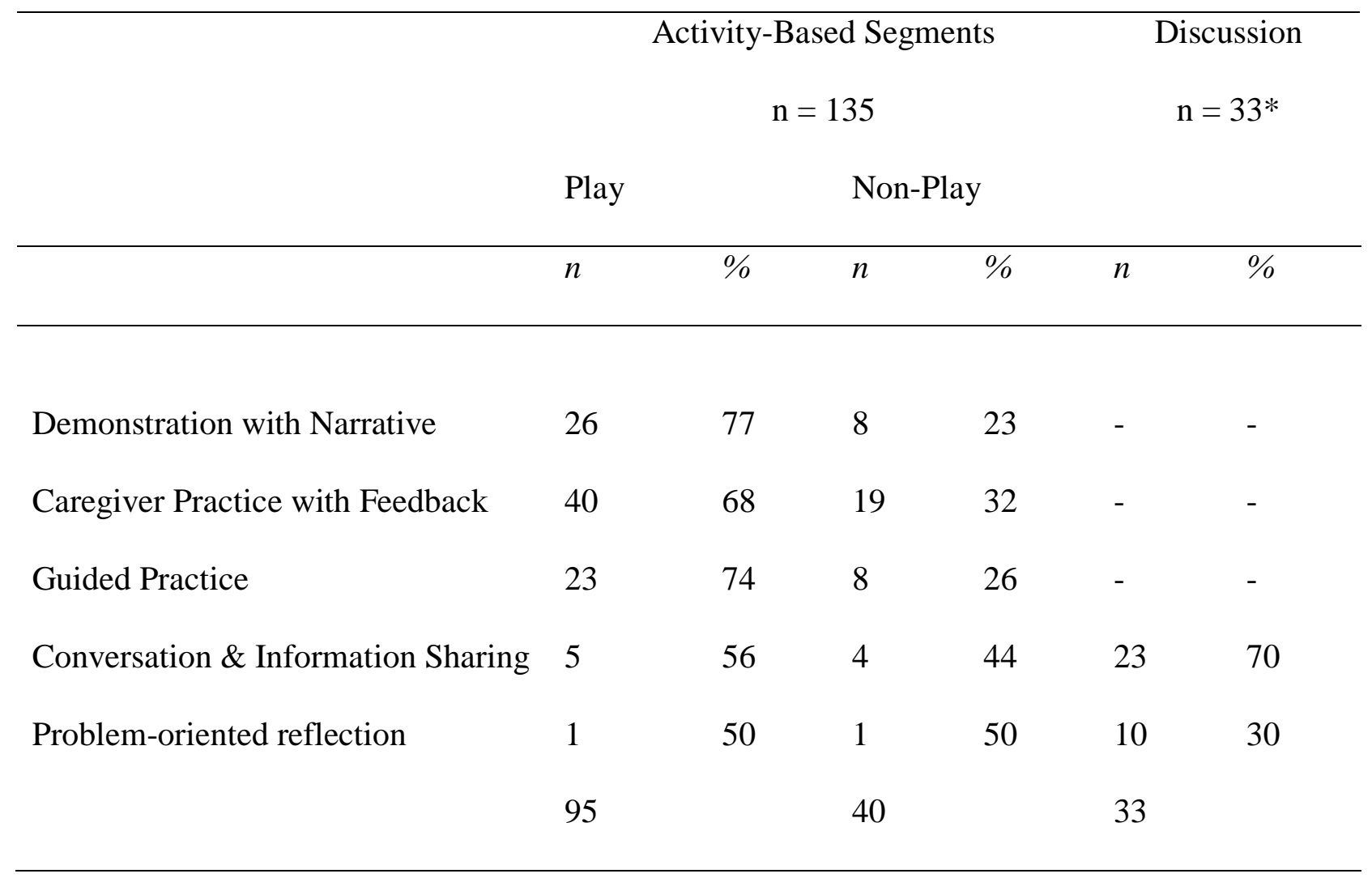

*These tapes were based on verbal discussion and there were no opportunities for demonstration with narrative, caregiver practice with feedback, or guided practice caregiver-teaching strategies. 
Table 4

Caregiver-Teaching Strategies and Functional Skill

\begin{tabular}{lllll}
\hline & & Activity-Based Segments \\
& Communication & Not Communication \\
& $\mathrm{n}=61$ & $\mathrm{n}=74$ & \\
& $\mathrm{n}$ & $\%$ & $\mathrm{n}$ & $\%$ \\
\hline Demonstration with Narrative & 18 & 53 & 16 & 47 \\
Caregiver Practice with Feedback & 27 & 46 & 32 & 54 \\
Guided Practice & 13 & 42 & 18 & 67 \\
Conversation \& Information Sharing & 3 & 33 & 6 & 2 \\
Problem-oriented Reflection & 0 & 0 & 2 & 74 \\
\hline
\end{tabular}

